\title{
Optimization of Rear Ordnance Depots Supply Business Process Based on GSPN
}

\author{
CHEN Jin, GAO Jun, LEI Mi \\ Equipment Command and Management Department, Mechanical Engineering College, \\ Shijiazhuang 050003, China
}

Keywords: GSPN model; rear ordnance depots; business process;cargo from storage

\begin{abstract}
Rear ordnance depots are important middle tones of our equipment support system.It's responsible for the campaign tasks of ordnance equipment storage and supply. Utilizing GSPN to analyze rear ordnance depots support business process quantitatively. Describe business process from the three aspects: average service time/resource using ration/average handling capacity and find the bottleneck constraints of timely,accurate,reliable ordnance support.Optimize the ordnance depots outbound business process and increase the efficiency of rear ordnance depots support.
\end{abstract}

\section{Introduction}

Ordnance depots are important forces in guaranteeing military activity in peacetime and wartime.Compared with common warehouse, It has the characteristics of many kinds/large number /higher safety requirements.In the management of ordnance depots business, although our army promulgated some related rules and regulations, these are just general and universal provisions in terms of personnel responsibilities, material receiving and storage. Rear ordnance depots support business process is a complex system. Various events interact mutually and accurate performance of business can't be understood only in descriptive language. Therefore, it's necessary to set up a quantitative model to analyze the ordnance depots support business process.

However, GSPN model can meet the needs. It can not only describe the development of system but can analyze the performance of the rear ordnance depots support business process as it has the same structure as Markov chain.

Cargo from storage is a vital business, This paper will focus on the analysis of the cargo from storage, in order to optimize the outbound process, improve the efficiency of the ordnance depot supply.

\section{Process and modeling of Rear ordnance depots outbound}

Generally, There are several steps of business process:Decision-making; Breaking-jam; Transporting-unloading; Posting; Site management.Accordingly,establish Petri model of outboundbusiness process.

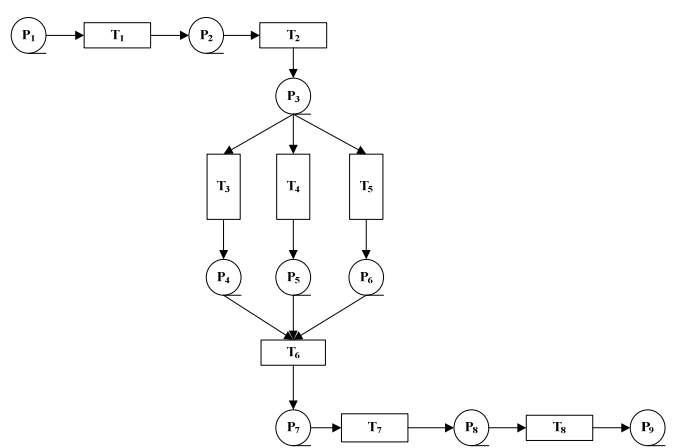

Fig 1 Modeling of Rear Ordnance Depot Outbound Business

Meanings of all places and changes:

Tab 1 Places and Changes of Petri Net Model

\begin{tabular}{cc} 
Limited set of & Limited set of \\
\hline
\end{tabular}




\begin{tabular}{ccc}
\hline & places $(\mathrm{P})$ & changes $(\mathrm{T})$ \\
\hline $\mathrm{P}_{1} /$ & Task received & Making plans \\
$\mathrm{T}_{1}$ & & \\
$\mathrm{P}_{2} /$ & Plan completed & Plan execution \\
$\mathrm{T}_{2}$ & & \\
$\mathrm{P}_{3} /$ & stock removal & Personnel division \\
$\mathrm{T}_{3}$ & & \\
$\mathrm{P}_{4} /$ & Staff ready & Instrument ready \\
$\mathrm{T}_{4}$ & & \\
$\mathrm{P}_{5} /$ & Instrument arrive & Accounts check \\
$\mathrm{T}_{5}$ & & \\
$\mathrm{P}_{6} /$ & Check ending & Unstacking Library \\
$\mathrm{T}_{6}$ & & \\
$\mathrm{P}_{7} /$ & Library complete & checking \\
$\mathrm{T}_{7}$ & & \\
$\mathrm{P}_{8} /$ & Check finished & Tissue loading \\
$\mathrm{T}_{8}$ & & \\
$\mathrm{P}$ & Loading & \\
& completed & \\
\hline
\end{tabular}

Its reachable marking graph can be deduced:

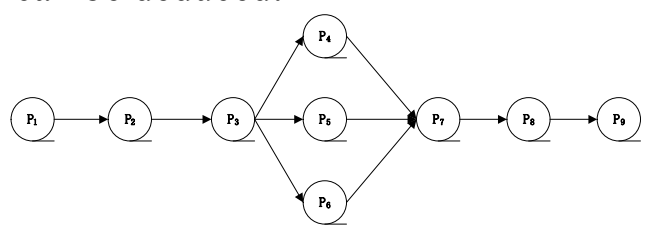

图4 后方弹药仓库供应保障Petri网可达标㻍图

Fig 2 Reaching Marking Graph of Petri net in Ordnance Depot Supply

Each of the reachable signs in the image can be expressed as follows:

$\begin{array}{cccccccccc} & P_{1} & P_{2} & P_{3} & P_{4} & P_{5} & P_{6} & P_{7} & P_{8} & P_{9} \\ M_{0} & 1 & 0 & 0 & 0 & 0 & 0 & 0 & 0 & 0 \\ M_{1} & 0 & 1 & 0 & 0 & 0 & 0 & 0 & 0 & 0 \\ M_{2} & 0 & 0 & 1 & 0 & 0 & 0 & 0 & 0 & 0 \\ M_{3} & 0 & 0 & 0 & 1 & 0 & 0 & 0 & 0 & 0 \\ M_{4} & 0 & 0 & 0 & 1 & 1 & 0 & 0 & 0 & 0 \\ M_{5} & 0 & 0 & 0 & 1 & 1 & 1 & 0 & 0 & 0 \\ M_{6} & 0 & 0 & 0 & 0 & 0 & 0 & 1 & 0 & 0 \\ M_{7} & 0 & 0 & 0 & 0 & 0 & 0 & 0 & 1 & 0 \\ M_{8} & 0 & 0 & 0 & 0 & 0 & 0 & 0 & 0 & 1\end{array}$

A Markov chain is available based on the matrix:

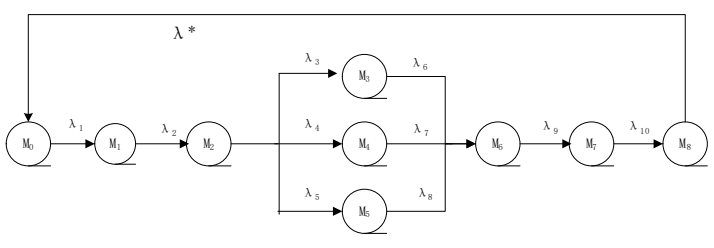

图5 同构的马尔科夫链

Fig 3 Isostructural Markov Chain

The transfer rate matrix $(\mathrm{Q})$ of the Markov process can be obtained according to the above graph. 
Then the MC state transfer process can be obtained.

$$
\left\{\begin{array}{l}
-\lambda_{1} P^{*}\left[M_{0}\right]+\lambda^{*} P^{*}\left[M_{8}\right]=0 \\
\lambda_{1} P^{*}\left[M_{0}\right]-\lambda_{2} P^{*}\left[M_{1}\right]=0 \\
\lambda_{2} P^{*}\left[M_{1}\right]-\left(\lambda_{3}+\lambda_{4}+\lambda_{5}\right) P^{*}\left[M_{2}\right]=0 \\
\lambda_{3} P^{*}\left[M_{2}\right]-\lambda_{5} P^{*}\left[M_{3}\right]=0 \\
\lambda_{4} P^{*}\left[M_{2}\right]-\lambda_{7} P^{*}\left[M_{4}\right]=0 \\
\lambda_{5} P^{*}\left[M_{2}\right]-\lambda_{8} P^{*}\left[M_{5}\right]=0 \\
\lambda_{8} P^{*}\left[M_{3}\right]+\lambda_{4} P^{*}\left[M_{4}\right]+\lambda_{8} P^{*}\left[M_{5}\right]-\lambda_{9} P^{*}\left[M_{6}\right]=0 \\
\lambda_{9} P^{*}\left[M_{6}\right]-\lambda_{10} P^{*}\left[M_{7}\right]=0 \\
\lambda_{10} P^{*}\left[M_{7}\right]-\lambda^{*} P^{*}\left[M_{8}\right]=0 \\
P^{*}\left[M_{0}\right]+P^{*}\left[M_{1}\right]+\cdots+P^{*}\left[M_{8}\right]=1
\end{array}\right.
$$

Solving the equations and get the steady state probability of $\mathrm{P}[\mathrm{M}]$ :

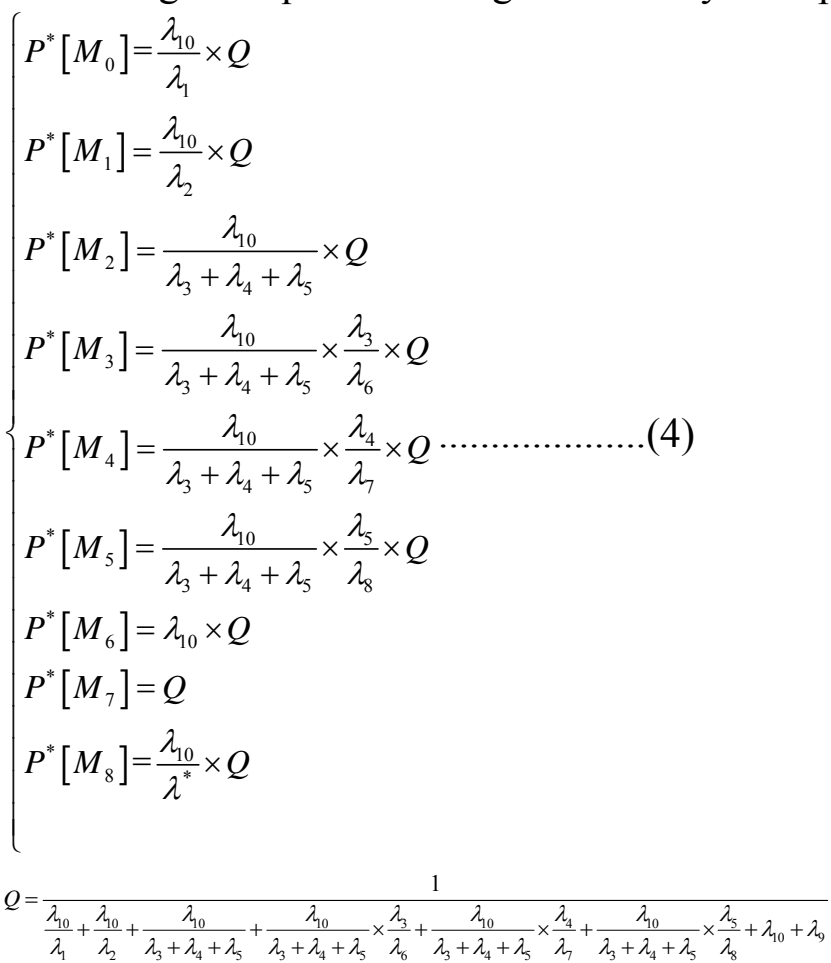

Once the value of $\lambda$ is given, the steady state probability $P^{*}\left[M_{i}\right]$ can be obtained by solving the equation, and then the performance of business process can be analyzed.

\section{Example analysis of rear ordnance depots business process based on GSPN}

\section{1 calculation of business process steady state probability}

Assuming a rear ordnance depot received an ordnance support task, each Initiation rate of transition in the model is shown in table2. 
Tab2 Rate Reference Values of Various Changes

\begin{tabular}{llll}
\hline $\begin{array}{l}\text { Initiation } \\
\text { rate }\end{array}$ & $\begin{array}{l}\text { Reference } \\
\text { value }\end{array}$ & $\begin{array}{l}\text { Initiation } \\
\text { rate }\end{array}$ & $\begin{array}{l}\text { Reference } \\
\text { value }\end{array}$ \\
\hline$\lambda_{1}$ & 0.5 & $\lambda_{6}$ & 5 \\
$\lambda_{2}$ & 2 & $\lambda_{7}$ & 8 \\
$\lambda_{3}$ & 1 & $\lambda_{8}$ & 2 \\
$\lambda_{4}$ & 2 & $\lambda_{9}$ & 1 \\
$\lambda_{5}$ & 0.5 & $\lambda_{10}$ & 0.3 \\
\hline
\end{tabular}

Set the value of $\lambda^{*}$ as 1 ,According to table 2 , the steady state probability of each library can be obtained,shown in Table 3.

Tab 3 Steady State Probability of Each Library

\begin{tabular}{llll}
\hline Library & $\begin{array}{l}\text { Steady state } \\
\text { probability }\end{array}$ & Library & $\begin{array}{l}\text { Steady state } \\
\text { probability }\end{array}$ \\
\hline$P^{*}\left[M_{0}\right]$ & $24.01 \%$ & $P^{*}\left[M_{5}\right]$ & $0.86 \%$ \\
$P^{*}\left[M_{1}\right]$ & $6.00 \%$ & $P^{*}\left[M_{6}\right]$ & $12.01 \%$ \\
$P^{*}\left[M_{2}\right]$ & $3.43 \%$ & $P^{*}\left[M_{7}\right]$ & $40.03 \%$ \\
$P^{*}\left[M_{3}\right]$ & $0.69 \%$ & $P^{*}\left[M_{8}\right]$ & $12.01 \%$ \\
$P^{*}\left[M_{4}\right]$ & $0.86 \%$ & & \\
\hline
\end{tabular}

\subsection{Analysis of business process performance index}

In the unit time, the number of change output by $t^{*}$ $f^{*}=\lambda \times P^{*}\left[M_{8}\right]=0.1201$

Calculate the average service time, that is, the average service time from the M0 to M8:

$T=\frac{1}{f^{*}}-\frac{1}{\lambda^{*}}=7.3264$

The paper only focuses on the utilization rate of human resources in ordnance depots. Assuming there are 3 kinds of human resources of rear ordnance depots-command personnel, business personnel, transport personnel.The matrix of library-resource $\mathrm{PR}_{3 \times 9}$ can be constructed.

$$
\gamma_{i j}=\left\{\begin{array}{l}
1 \\
0
\end{array}(\text { If } " J " \text { doesn't contain " } i ")\right.
$$

Each library is in busy state if there is a resource and calculate the probability of each library.

$$
\left\{\begin{array}{l}
P\left(P_{1}=1\right)=P^{*}\left[\mathrm{M}_{0}\right] \\
P\left(P_{2}=1\right)=P^{*}\left[\mathrm{M}_{1}\right] \\
P\left(P_{3}=1\right)=P^{*}\left[\mathrm{M}_{2}\right] \\
P\left(P_{4}=1\right)=P^{*}\left[\mathrm{M}_{3}\right]+P^{*}\left[\mathrm{M}_{4}\right]+P^{*}\left[\mathrm{M}_{5}\right] \\
P\left(P_{5}=1\right)=P^{*}\left[\mathrm{M}_{4}\right]+P^{*}\left[\mathrm{M}_{5}\right] \\
P\left(P_{6}=1\right)=P^{*}\left[\mathrm{M}_{5}\right] \\
P\left(P_{7}=1\right)=P^{*}\left[\mathrm{M}_{6}\right] \\
P\left(P_{8}=1\right)=P^{*}\left[\mathrm{M}_{7}\right] \\
P\left(P_{9}=1\right)=P^{*}\left[\mathrm{M}_{8}\right]
\end{array}\right.
$$

Vector can be known,

$T N=[0.2401,0.0600,0.0343,0.0241,0.0172,0.0086,0.1201,0.4003,0.1201]^{-1}$ and according to the formula(2),get the following matrix: 
$\mathrm{PR}_{3 \times 9}=\left[\begin{array}{ccccccccc}0 & 1 & 0 & 0 & 1 & 0 & 0 & 0 & 0 \\ 0 & 0 & 0 & 1 & 1 & 1 & 0 & 0 & 0 \\ 0 & 0 & 0 & 0 & 0 & 1 & 0 & 1 & 0\end{array}\right]$

Define vector(TN) as the column vector of busy probability of each library, then the utilization rate of ordnance depots in human resources is shown in Formula (10).

$N=P R \times T N$

According to the formula(3),the utilization rate of depots human resources can be obtained.

Tab 4 utilizing rate of rear ordnance depot human resources

\begin{tabular}{ll}
\hline Human resource category & utilization \\
\hline Conductor & $33.4 \%$ \\
Service personnel & $21.7 \%$ \\
Transport personnel & $32.9 \%$ \\
\hline
\end{tabular}

The average mark velocity of $\mathrm{T} 0$ can reflect the average throughput capacity, Thus,average mark velocity of Petri Net in rear ordnance depots is:

$R(\mathrm{t}, \mathrm{s})=U(\mathrm{t}) \times \lambda=0.1201$

\section{Optimization of Rear Ordnance Depots Support Business Process Based on GSPN}

Based on the front case, establish improved model of ordnance supply support business process and analyzed,good results are gotten compared to the original model.

There are too more supply business processes so that the system is rigid and slow.

With the army information continuously promoting,the interactive degree of rear ordnance depots support command system with others are improving.Real-time transmission of information can be realized, grasp the needs of ordnance equipment support and release ordnance equipment support task in time.convey P1 to P3 by T3.Inform relevant personnel to do library preparation and enhance the speed of ordnance equipment support.

There are 8 changes totally and two of them carry on checking account,quantity of material,quality testing.According to the Petri network structure,merging the process model can reduce time consumption,improve the support efficiency.Average identification number of each library in the support system can be calculated.Average identification number of P8 is 0.4003 because of the slow task execution.support efficiency will be improved by RFID.

Improve the ordnance depots supply business process and the improved results are as follows:

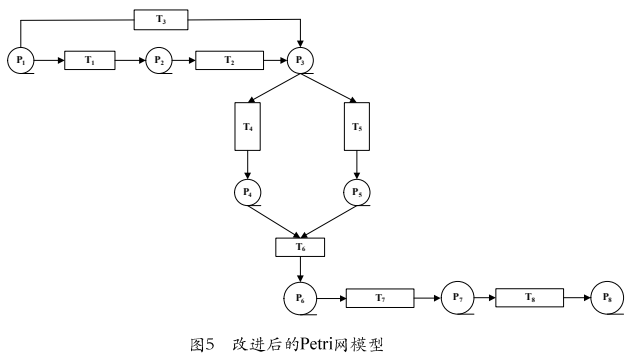

Fig 4 Improved Petri Net Model 
Tab 5 Meanings of All Places and Changes

\begin{tabular}{ccc}
\hline & Limited set of places $(\mathrm{P})$ & $\begin{array}{c}\text { Limited set of } \\
\text { changes }(\mathrm{T})\end{array}$ \\
\hline $\mathrm{P}_{1} / \mathrm{T}_{1}$ & Task received & Making plans \\
$\mathrm{P}_{2} / \mathrm{T}_{2}$ & Plan completed & Plan execution \\
$\mathrm{P}_{3} / \mathrm{T}_{3}$ & Start outbound & Outbound ready \\
$\mathrm{P}_{4} / \mathrm{T}_{4}$ & Staff ready & Personnel division \\
$\mathrm{P}_{5} / \mathrm{T}_{5}$ & Instrument arrive & Instrument ready \\
$\mathrm{P}_{6} / \mathrm{T}_{6}$ & Unstacking Library & Unstacking Library \\
$\mathrm{P}_{7} / \mathrm{T}_{7}$ & Check finished & checking \\
$\mathrm{P}_{8} / \mathrm{T}_{8}$ & Loading completed & Tissue loading \\
\hline
\end{tabular}

Set up improved reachable marking graph of petri net:

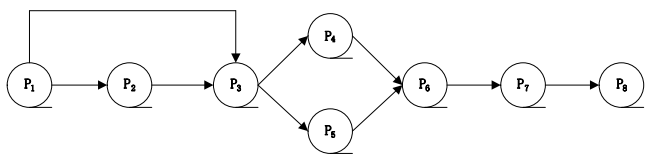

图6 改进后的Petri网模型的可 达标志图

Fig 5 Improved Reachable Marking Graph

Each reachable marking flow matrix:

$\begin{array}{ccccccccc} & P_{1} & P_{2} & P_{3} & P_{4} & P_{5} & P_{6} & P_{7} & P_{8} \\ M_{0} & 1 & 0 & 0 & 0 & 0 & 0 & 0 & 0 \\ M_{1} & 0 & 1 & 1 & 0 & 0 & 0 & 0 & 0 \\ M_{2} & 0 & 0 & 1 & 0 & 0 & 0 & 0 & 0 \\ M_{3} & 0 & 0 & 0 & 1 & 1 & 0 & 0 & 0 \\ M_{4} & 0 & 0 & 0 & 0 & 1 & 0 & 0 & 0 \\ M_{5} & 0 & 0 & 0 & 0 & 0 & 1 & 0 & 0 \\ M_{6} & 0 & 0 & 0 & 0 & 0 & 0 & 1 & 0 \\ M_{7} & 0 & 0 & 0 & 0 & 0 & 0 & 0 & 1\end{array}$

The isostructural MC can be obtained:

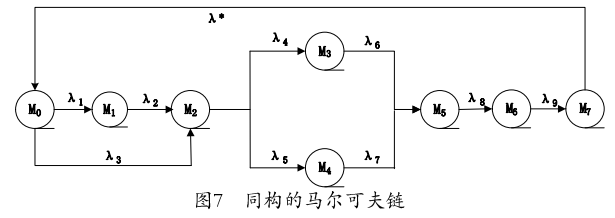

Fig 6 Isostructural MC

The transfer matrix $\mathrm{Q}$ of $\mathrm{MC}$ is :

$Q=\left[\begin{array}{cccccccc}-\left(\lambda_{1}+\lambda_{3}\right) & \lambda_{1} & \lambda_{3} & 0 & 0 & 0 & 0 & 0 \\ 0 & -\lambda_{2} & \lambda_{2} & 0 & 0 & 0 & 0 & 0 \\ 0 & 0 & -\left(\lambda_{4}+\lambda_{5}\right) & \lambda_{4} & \lambda_{5} & 0 & 0 & 0 \\ 0 & 0 & 0 & -\lambda_{6} & 0 & \lambda_{6} & 0 & 0 \\ 0 & 0 & 0 & 0 & -\lambda_{7} & \lambda_{7} & 0 & 0 \\ 0 & 0 & 0 & 0 & 0 & -\lambda_{8} & \lambda_{8} & 0 \\ 0 & 0 & 0 & 0 & 0 & 0 & -\lambda_{9} & \lambda_{9} \\ \lambda^{*} & 0 & 0 & 0 & 0 & 0 & 0 & -\lambda^{*}\end{array}\right]$

The Markov state transfer equation:

$$
\left\{\begin{array}{l}
-\left(\lambda_{1}+\lambda_{3}\right) P^{*}\left[M_{0}\right]+\lambda^{*} P^{*}\left[M_{7}\right]=0 \\
\lambda_{1} P^{*}\left[M_{0}\right]-\lambda_{2} P^{*}\left[M_{1}\right]=0 \\
\lambda_{3} P^{*}\left[M_{0}\right]+\lambda_{2} P^{*}\left[M_{1}\right]-\left(\lambda_{4}+\lambda_{5}\right) P^{*}\left[M_{2}\right]=0 \\
\lambda_{4} P^{*}\left[M_{2}\right]-\lambda_{6} x^{*}\left[M_{3}\right]=0 \\
\lambda_{5} P^{*}\left[M_{2}\right]-\lambda_{2} P^{*}\left[M_{4}\right]=0 \\
\lambda_{6} E^{*}\left[M_{3}\right]+\lambda_{2} P^{*}\left[M_{4}\right]-\lambda_{8} P^{*}\left[M_{5}\right]=0 \\
\lambda_{8} P^{*}\left[M_{5}\right]-\lambda_{9} P^{*}\left[M_{6}\right]=0 \\
\lambda_{9} P^{*}\left[M_{6}\right]-\lambda^{*} P^{*}\left[M_{7}\right]=0 \\
P^{*}\left[M_{0}\right]+P^{*}\left[M_{1}\right]+\cdots+P^{*}\left[M_{7}\right]=1
\end{array}\right.
$$


After improvement of outbound business process, velocity of part $\lambda$ changed:

Tab 6 Rate Reference Values after Optimizing

\begin{tabular}{cccc}
\hline $\begin{array}{c}\text { Initiation } \\
\text { rate }\end{array}$ & $\begin{array}{c}\text { Referenc } \\
\text { e value }\end{array}$ & $\begin{array}{c}\text { Initiation } \\
\text { rate }\end{array}$ & $\begin{array}{c}\text { Referenc } \\
\text { e value }\end{array}$ \\
\hline$\lambda_{1}$ & 0.5 & $\lambda_{6}$ & 2 \\
$\lambda_{2}$ & 2 & $\lambda_{7}$ & 4 \\
$\lambda_{3}$ & 1 & $\lambda_{8}$ & 5 \\
$\lambda_{4}$ & 2 & $\lambda_{9}$ & 1.2 \\
$\lambda_{5}$ & 3 & $\lambda^{*}$ & 1 \\
\hline
\end{tabular}

The steady state probability of each library can be gotten by solving equations:

\begin{tabular}{rccc}
\hline library & $\begin{array}{c}\text { Steady } \\
\text { probability }\end{array}$ & library & $\begin{array}{c}\text { Steady } \\
\text { probability }\end{array}$ \\
\hline$P^{*}\left[M_{0}\right]$ & $20.73 \%$ & $P^{*}\left[M_{4}\right]$ & $6.22 \%$ \\
$P^{*}\left[M_{1}\right]$ & $5.18 \%$ & $P^{*}\left[M_{5}\right]$ & $25.91 \%$ \\
$P^{*}\left[M_{2}\right]$ & $6.22 \%$ & $P^{*}\left[M_{6}\right]$ & $31.09 \%$ \\
$P^{*}\left[M_{3}\right]$ & $6.22 \%$ & $P^{*}\left[M_{7}\right]$ & $4.66 \%$
\end{tabular}

The average service time of the improved Petri net model is obtained:

$T=\frac{1}{f^{*}}-\frac{1}{\lambda^{*}}=5.2364$

The utilization of various human resources in the improved Petri net model is shown in the following table.

Tab 8 Utilization of Human Resources in The Improved Model

\begin{tabular}{ll}
\hline Human resources category & utilization \\
\hline Conductor & $37.9 \%$ \\
Service personnel & $46.4 \%$ \\
Transport personnel & $55.3 \%$ \\
\hline
\end{tabular}

The average marking velocity of improved model is:

$R(t, s)=U(t) \times \lambda=0.3731$

Do some comparison of outbound business process before and after improving.

\begin{tabular}{l|c|c|c|c}
\hline \multicolumn{2}{c}{} & \multicolumn{1}{c}{$\begin{array}{c}\text { original } \\
\text { business } \\
\text { process }\end{array}$} & $\begin{array}{c}\text { Improved } \\
\text { business } \\
\text { process }\end{array}$ & $\begin{array}{c}\text { Improvement } \\
\text { degree }\end{array}$ \\
\hline \multicolumn{2}{l}{ Average service time } & 7.3264 & 5.7389 & $-21.66 \%$ \\
\hline \multirow{2}{*}{$\begin{array}{l}\text { Utilizing of } \\
\text { resources }\end{array}$} & $\mathrm{r}_{1}$ & $33.40 \%$ & $37.90 \%$ & $+4.5 \%$ \\
\cline { 2 - 5 } & $\mathrm{r}_{2}$ & $21.70 \%$ & $46.40 \%$ & $+24.7 \%$ \\
\cline { 2 - 5 } & $\mathrm{r}_{3}$ & $32.90 \%$ & $55.30 \%$ & $+22.4 \%$ \\
\hline \multicolumn{2}{l}{$\begin{array}{l}\text { Average marking } \\
\text { velocity }\end{array}$} & 0.1201 & 0.3731 & +0.253 \\
\hline
\end{tabular}

A conclusion can be drawn:By improving t-he rear ordnance outbound business process ,the average service time reduce $21.66 \%$, utilization of human resources Greatly increased,and the average 


\section{Conclusion}

This paper describes the system of ordnance depots outbound business process,analyzed the related performance of the process model Find out the bottleneck of restricting the supply support efficiency.The three performance index increases greatly .It's significant to improve the ordnance depot support effectiveness.

\section{Reference}

[1] Kang zhiyuan.A study of Business Process Reengineering Based on Petri Net[C].Proceedings of 2010 Second International Seminar on Business and Information Management (ISBIM 2010).2010

[2]Liang Qingguo.Research on THE Ordnance Maintenance Materials Depot Operation Management Method[D],Ordnance Engineering College,2004.

[3] Ge Yang.Research on Decision-Making Methods for Storage and Logistics of Ordnance Maintenance Materials[D]Ordnance Engineering College,2010.

[4]Wen Yang,Yuehui Jin,Tan Yang.An incidence Matrix-Based Verification Method for Business Process Model In Inter-Domain Network Management System[C].Proceedings of $201315^{\text {th }}$ IEEE International Conference on Communication Technology 2013.

[5] Yan Zhijun, Gan Renchu. Formalization and Verification of Business Process Modeling Based on UML and Petri Nets[J].Journal of Beijing Institute of Technology(English Edition),2005,(2).

[6] Yuan Chongyi, Zhao wen, Zhang Shikun,A Three-layer Model for Business Process logic, Case Semantics and Work Flow Management[J].Journal of Computer Science \& Technology,2007,(3).

[7] Maryam,Majad Moradi. A Framework for change Management in Business Process Modeling[C].Proceedings of 2012 International Conference on Network and Computer Science,2012. 